\title{
Site-specific Based Models
}

Cesar Fernández-Quintanilla, José Dorado, Dionisio Andújar, and J. M. Peña

\begin{abstract}
This chapter reviews the major conceptual approaches and specifications for the design of Site-Specific Weed Management Decision Support Systems (SSWM-DSS), recent advances in the use of remote and ground platforms and sensors for information gathering and processing and initial experiences translating this information into chemical and physical weed control actuations through decision algorithms and models.
\end{abstract}

Keywords Site-specific $\cdot$ Weed management $\cdot$ DSS design $*$ Prescription maps $\cdot$ Online decisions $\cdot$ Sensors $\cdot$ Aerial images

\section{Introduction}

The advent of geospatial technologies (GPS, GIS), information and communication technologies (ICT), new soil and plant sensors and advanced agricultural machinery has opened the possibility of careful tailoring of soil and crop management to fit the different conditions found in each field. This concept has received different names: precision agriculture, precision farming, smart agriculture. Site-specific weed management (SSWM) is the application of this concept to one particular aspect of agricultural production: weed control. Site-specific weed management is based on the fact that weed populations are commonly irregularly distributed within crop fields and it implies applying chemical and/or physical weed control measures only where and when they are really needed (Christensen et al., 2009).

Decision models for weed management can be divided into either efficacy-based or population-based. The efficacy-based systems assist decision-makers in choosing herbicide products and doses. Populationbased models incorporate weed biology and ecology through simple, deterministic models e.g. threshold models where plant densities above a specified economic threshold are controlled. The efficacy-based systems comprises large databases with herbicide performances in different crops, weed species, growth stages etc., enabling ranking and recommendations of

C. Fernandez-Quintanilla $\square$, J. Dorado, D. Andújar, J.M. Peña Consejo Superior de Investigaciones Científicas (CSIC) Instituto de Ciencias Agrarias, Madrid, Spain e-mail: cesar@ica.csic.es; jose.dorado@csic.es; d.andujar@csic.es; jmpena@ica.csic.es; 
the most efficient product and dose against a weed mixture. In the population-based systems, the estimated yield loss or changes in the soil seed bank without weed control define the need for weed control and determine whether weed control will be cost-effective.

Although a large number of weed management Decision Support Systems (DSS) have been developed in the past in various European countries

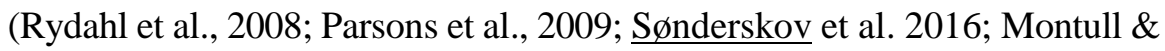
Rydahll, 2019) and in the US (Neeser et al, 2004) all of them have ignored the spatial variation of weed populations within a field. This is a serious limitation. The use of field-scale mean density estimates in spatially heterogeneous weed populations results in under-prediction of yield loss at locations where weed density is high and over-prediction in parts of the field where weed densities are low or weeds are absent. Consequently, uniform herbicide application based on fixed economic weed thresholds is likely to result in under-application in some parts of the field and over-application in others.

In order to avoid this problem, it would be required to integrate sitespecific information about weed species composition and density, knowledge about crop-weed competition, the effect on crop yield and quality and the species-specific efficacies of possible control methods. The effect of soil conditions, crop husbandry and machinery are also variables that have significant influence on the emergence, competition and propagation of different weed species, and are also important for decision making. The infinite combination of biological and agronomic variables with the range of efficacies of all possible control methods generates a need for SSWM-DSS that optimise economic goals and meets environmental constraints.

Building SSWM-DSS needs, as a logical starting point, defining specific decisions (e.g. patch spraying) and the minimum spatial and temporal datasets needed to make those decisions, at both temporal and spatial scales. In other words, providing 'the right data at the right time' (Yost et al., 2019). Different types of data may be needed for real-time decisions (e.g. for online spraying) than for generation of weed maps (e.g. for prescription maps based on historical data). Furthermore, decisions and definitions of minimum data will be different for each scale (e.g., individual plant, management zone, field, farm). 


\section{Conceptual Approaches for the Design of SSWM-DSS}

Several commercial and public DSS have been developed to be used in precision agriculture (Yost et al., 2019). Although they are mainly focused on $\mathrm{N}$ fertilization and irrigation practices, some of the basic concepts used in these systems could be applied to weed management. According to Yost el al (2019) usable models and DSS for on-farm sub-field management decisions should include:

1. Improved understanding of underlying mechanisms. Fundamental research on how incremental herbicide rates input changes affect outcomes is needed as differential responses may be accurate while absolute outcomes may not.

2. More synergy and synchrony between data generators (e.g. synergistic use of diagnostic environmental sensors and models for accurate and ongoing parameterization).

3. Better incorporation of end-user input and data. This may include translation of collected data to management parameters and decisions from grower's perspective in order to connect them to their property and feedback loop from farmer to consultant for better utilization of models to ensure farmer observations are incorporated.

The first decision algorithm specifically designed for patch spraying (DAPS) was developed by Christensen et al. (2003). The main components of DAPS were:

1. A crop-weed competition model that estimates yield loss as a function of weed species and their densities.

2. A model that estimates yield gain and net return as a function of herbicide dose and weed species composition and responses.

3. An algorithm that finds the economically optimal herbicide dose of a given weed mixture.

This model, in combination with an appropriate sensor system for weed recognition and classification as well as an improved application technology, allows variable rates and herbicide mixtures in real-time. The results of a five-year field experiment designed to assess this model under field conditions showed that optimisation of the dosage to the local weed species 
composition and densities every year reduced herbicide usage 45-67\% without reducing the crop yield or increasing the density of the weed population.

Lamastus-Stanford \& Shaw (2004) adapted HADSS, a computerized yield loss and post emergence herbicide selection decision aid, to the variable weed populations present in various soybean fields. To determine the effect of a SSWM program on the net returns and amount of herbicide applied to the fields, weed populations for each sample location within each field were subjected to HADSS, using various sampling scales $(10 \times 10 \mathrm{~m}, 40 \times 40 \mathrm{~m}, 60 \times 60 \mathrm{~m}$ and $80 \times 80 \mathrm{~m})$. These researchers demonstrated the potential value of SSWM from an economic standpoint. The differences between projected net returns from SSWM and the broadcast applications ranged from $\$ 10.42$ to $\$ 14.1 \mathrm{ha}^{-1}$. Results from larger, less-intense sampling scales, were not significantly different.

Gutjar \& Gerhards (2010) developed HPS-ONLINE, another decision model developed for site-specific herbicide application. This model can be divided into two parts:

1. Knowledge before application. Although HPS-ONLINE offers the possibility for the implementation of population dynamics aspects for weed control, in this program the model user is able to choose the importance of this aspect himself. If the user is planning to use long crop rotation intervals or narrow row spacings the population dynamics aspects may be disregarded. Regarding weather conditions, if the user considers that conditions are optimal for herbicide application, HPSONLINE offers the possibility for a general reduction of herbicide dose. This implementation of users` expert knowledge and experience is a valuable component of this system.

2. Knowledge during application. The system uses the weed coverage at the time of weed control for the estimation of weed competition. This data is obtained automatically using a bispectral sensor system. Plant species are classified in four categories (crop and three weed types) by their shape features using an automatic classifier. Based on this information, a separate application decision is made for each weed class. 
Fernandez-Quintanilla et al (2011) proposed the basic specifications for the design of a DSS based on spatio-temporal information on weed infestations. This proposal, designed to be used by a fleet of patch-spraying robots, was structured in five modules (Fig 1):

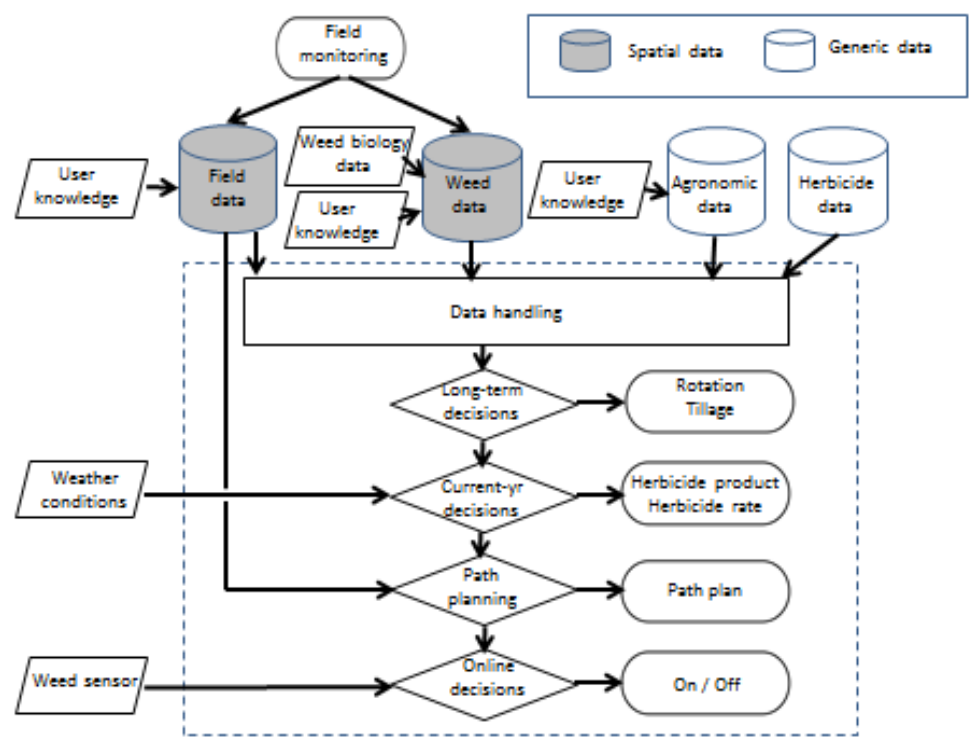

Fig. 1. Proposed system architecture for a SSWM-DSS for a fleet of robots

1. Current year decisions. This is a complex decision requiring the integration of information on weed biology, expected crop yields and potential yield losses caused by different weeds, herbicide options, timing and efficacy of each herbicide, influence of climatic conditions, economic profitability of the treatment and herbicide resistance risks. Nowadays agricultural growers and consultants can manage the integration of these complex factors by using available DSS (Parsons et al., 2009; Montull \& Rydahl, 2019).

2. Unit distribution \& path planning. The objective of this module is to plan the routes to be followed by each individual robotic unit, taking into consideration the geometry of the field, the strategy of the operation and the spatial distribution of weeds. 
3. Online decisions. Although prescription maps may provide the basic information of the field areas that should be sprayed, this information needs to be contrasted with that obtained at spraying time with cameras or sensors that detect weed presence and discriminate different weed types. Once the detected weed patch has been considered as a suitable target for spraying, a fast-response controller could regulate discharge of the different herbicides in each individual nozzle.

Decisions derived from DSS should not be considered as compulsory operations to be conducted by the farmer but as recommendations to be considered in his final, personal decision. In any case, it is desirable to assess the results obtained from the application of those final decisions. This assessment should take into consideration agronomic, economic and environmental criteria. In order to do that it would be required to collect data at the field scale (e.g. total herbicide use, total yield, etc.) and at the subfield scale (e.g. yield mapping, weed mapping at harvest time, etc.).

\section{Using Remote-Sensed Images to Construct Prescription Maps}

Remote sensing technology can provide spatial and temporal information on the presence and absence of weeds at the field scale as key input data to feed a DSS. The primary phase consists in classifying the remote-sensed images into a weed map that shows the weed plants or the weed patches. Prior to the widespread use of drones, remote images taken with piloted aircrafts or satellite platforms allowed to detect large weed patches (at least $2 \mathrm{~m}$ by 10 $\mathrm{m}$ in size) with a low resolution. This fact limited the potential implementation of this technology to late-season inspection of crop fields with large weed patches (Brown \& Noble, 2005). Early studies used highaltitude images for late-season weed discrimination in cereal and legume crops, soybean and sunflower (Gomez-Candon et al., 2012a; de Castro et al., 2012, 2013; Gray et al., 2008; Peña-Barragán et al., 2007). However, although weed control treatments at a late crop stage are generally inappropriate or ineffective, these weed maps may be useful for weed control in the following year if weed patches are spatially stable over time, such as those of Avena sterilis (Barroso et al., 2004), Ridolfia segetum (Peña-Barragán et al., 2007) and Alopecurus myosuroides (Lambert et al., 
2017). These late-season maps may also have other uses, e.g. relating weed infestations and crop yields (Gutiérrez et al., 2008; Peña-Barragán et al., 2010), assessing the impact or efficiency of specific weed control treatments (Franco et al., 2017;. Huang et al., 2018; Rasmussen et al., 2013), studying weed population dynamics (Castillejo-González et al., 2019). Spatial resolution of the remote images (i.e., pixel size) is a key parameter to the success of weed detection and mapping. Hengl (2006) considered that pixel size should be at least a quarter of the target element (in our case, the weed plant or patch). Currently, drones generally provide remote images of a few centimeters and, in some cases, of less than one millimeter. This feature allows weed detection at very early stages of the crop and weeds, the critical period for weed treatments (Pflanz et al., 2018; Torres-Sánchez et al., 2013). Several investigations have demonstrated the capability of early-season drone-based images to detect weeds in maize (Castaldi et al., 2017; Gao et al., 2018; Peña et al., 2013; Pérez-Ortiz et al., 2016), sunflower (LópezGranados et al., 2016; Pérez-Ortiz et al., 2015, 2016), barley (Franco et al., 2017; Rasmussen et al., 2013), wheat (Jurado-Expósito et al., 2019; Pflanz et al., 2018), vineyards (Jiménez-Brenes et al., 2019), and rice (Huang et al., 2018a, b). High resolution weed maps can be generated by combining advanced object-based image analysis (OBIA) techniques and machine learning algorithms (de Castro et al., 2018; Gao et al., 2018; Perez Ortiz et al., 2016; Pflanz et al., 2018) (Fig. 2). These procedures usually incorporate spatial and spectral information of each plant previously segmented as objects within the images. Classification algorithms are usually more effective in row-crops, where the position of the weeds relative to the croprow is generally a decisive factor (Louargant et al., 2018; Peña et al., 2013).

In order to practice SSWM, a subsequent phase consists on converting weed maps to prescription maps. These maps are a set of grids with the corresponding weed infestation values (weed coverage or weed density). The prescription maps also provide additional information on the crop field and crop development. This information is important to design and apply DSS. Peña et al. (2013) developed an OBIA procedure based on a dronebased weed map in maize. This procedure consists in three levels of information according to the spatial scale of field observation. The upper level provides global information of the crop field, including field dimensions, number of crop rows, crop row orientation, average crop row 
separation and total weed-free and weed-infested areas, including total area of three different categories of weed coverage (low, moderate and high).

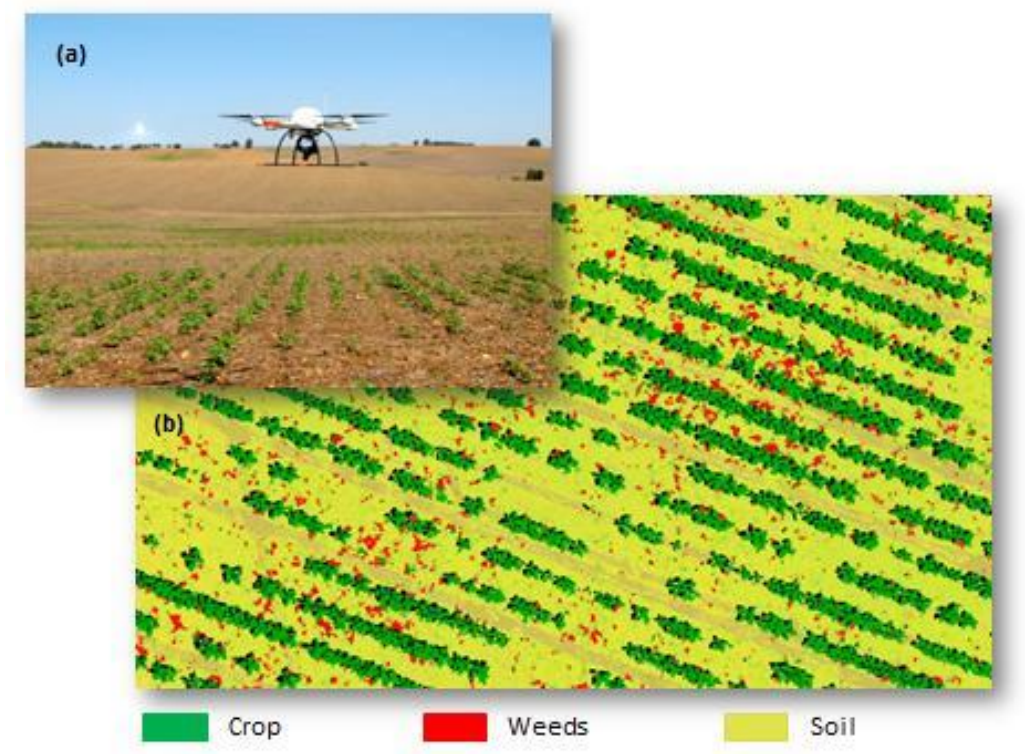

Fig 2. (a) Using an Unmanned Aerial Vehicle (UAV) flying at $30 \mathrm{~m}$ altitude over a sunflower field to detect weed infestations. (b) Classified image by applying an auto-trained Random Forest classifier Object Based Image Analysis (RF-OBIA) algorithm (de Castro et al, 2018).

The intermediate level provides detailed information on each crop row, including identification number, length, width, coordinates of the extremes and number and category of the weed-infested grids of each row. Finally, the lower level provides detailed information on each grid unit, including identification number, coordinates, dimensions, relative position within the crop row, distance to the start and the end of the crop row, weed coverage percentage and weed coverage category of each grid. For the development of a DSS, this dataset at the three levels enables to estimate the total area that needs weed treatment, and therefore, calculate the herbicide volume needed prior to its application, as well as the location of the weed-infested grids, the orientation of the crop rows and the general pattern of the crop 
field, which is fundamental to plan treatment routes and optimize the tractor trajectory (Gonzalez-de-Santos et al., 2016).

Generally, the prescription maps are exported to the sprayer to conduct the treatment according to the position of each grid and the weedtreatment decision (e.g spray or do not spray) following a SSWM strategy. The ultimate objective is decreasing the amount of herbicide in comparison to a uniform weed treatment. In their study, Peña et al (2013) determined that the area free of weeds and with low weed coverage ( $<5 \%$ weeds) was $23 \%$ and $47 \%$, respectively, which demonstrated the high potential for reducing herbicide applications in this case study. Castaldi et al. (2017), working also in maize crops, designed prescription maps of $2 \mathrm{~m} \times 2 \mathrm{~m}$ in size from drone images and reported herbicide savings between 14 and $39.2 \%$ for patch spraying as compared to a blanket application.

However, overall herbicide savings would vary depending on the level of weed infestation, the criteria established for herbicide application and the size of the spray grid considered. Gómez-Candón et al. (2012 a, b,) evaluated the impact of these variables on herbicide savings by using aerial images for mapping Avena sterilis in wheat fields and reported that the herbicide savings increased from $20 \%$ to $90 \%$ for weed treatment thresholds of $0 \%$ and $30 \%$ of weed coverage, respectively (Fig. 2). These authors also indicated that treatment efficiency increases three times as much if the grid size is reduced from $20 \mathrm{~m} \times 6 \mathrm{~m}$ (i.e., for the entire sprayer platform) to 1.2 $\mathrm{m} \times 1.5 \mathrm{~m}$ (i.e., for individual nozzles). Lopez-Granados et al. (2016), using images from two sunflower fields, studied the variability of herbicide treatment maps generated from UAV images using weed thresholds ranging from $0 \%$ to $15 \%$. The results obtained showed that the total area of weed treatment decreased from a maximum area of $46 \%$ at a weed threshold of $0 \%$, to a minimum area of $3 \%$ at a weed threshold of $15 \%$. This study also evaluated the impact of flight altitude (i.e., image spatial resolution) and type of camera (i.e., RGB vs. multi-spectral) in the accuracy of the prescription maps as affected by the studied weed thresholds. The results showed that the multispectral camera was better than the RGB camera in all cases and that reasonable accuracy (i.e., overall accuracy $>85 \%$ ) was obtained from weed thresholds above $2.5-5 \%$ on average with both cameras. Huang et al. (2018), using UAV-based images on rice fields for the generation of prescription maps, also quantified high herbicide savings 
depending on the treatment threshold used, reporting savings between 58 and $71 \%$ for weed coverage thresholds of $0 \%$ to $25 \%$, respectively.
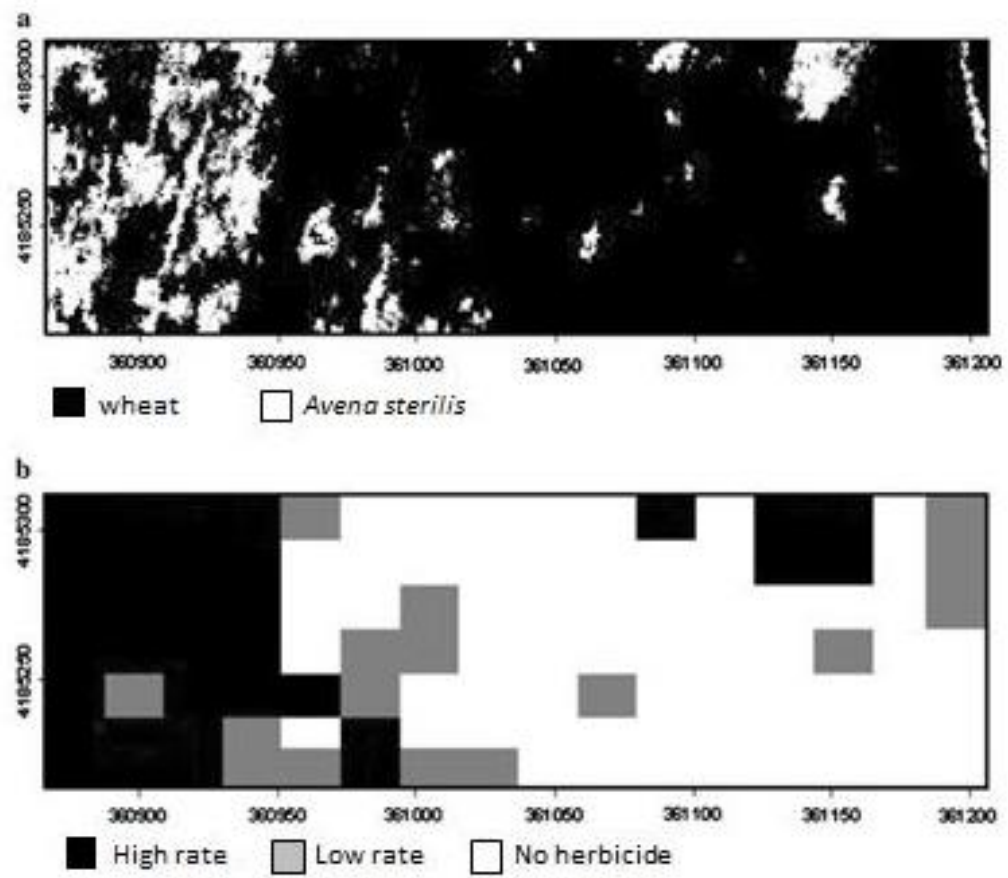

Fig. 3. Using aerial images to design herbicide application: (a) NVDI image view of a winter wheat field infested with Avena sterilis. Original RGB images obtained from a plane flying at $1500 \mathrm{~m}$ altitude; (b) herbicide prescription map with three classes: high rates when $>26 \%$ infested pixels, low rates when 11 to $26 \%$ infested pixels and no herbicide when $<11 \%$ infested pixels (Gomez-Candon et al., 2012)

\section{Using Ground Sensing Imagery to Make Online Decisions}

Farmers are more likely to adopt embodied technologies that do not require acquiring additional skills (e.g. smart online sprayers) than information intensive technologies that require special skills (e.g. weed mapping from aerial images) (Lutman \& Miller, 2007; Griffin, 2016). The data required to take online decisions can be obtained from different types of sensors or cameras. 
The simplest devices are spectral reflectance sensors. This technology, developed originally by Felton \& McCloy (1992), is based on the fact that the spectral curve of plants differs significantly from the reflectance of soil. Consequently, if these sensors are located in crop-free areas (e.g. inter-rows, tramlines, fallow land) the decision to be made is simple and can be taken in milliseconds: all green detected objects are supposed to be weeds and should be sprayed. This principle has been widely used in the past for real-time patch spraying of herbicides (Felton \& McCloy,1992; Dammer \& Wartenberg, 2007; Dammer, 2016). However, since crops and weeds cannot be discriminated with these sensors, this approach has important limitations.

Weed plants can be discriminated from other elements in the image (soil, crop) by using three sequential processes (Fernandez-Quintanilla et al., 2018):

1. Segmentation of the original image, obtaining an image with white pixels representing plant cover and black pixels depicting soil.

2. Identification of zones corresponding to crop rows, quantifying crop cover and eliminating these pixels.

3. Estimation of weed cover after the improvement of image by filtering noise and errors from previous steps

Up to now, the most widely used technique for crop-weed discrimination is based on imaging with sensitive sensors within the range of the visible light (Peteinatos et al., 2014). Relatively low-cost and easily operated RGB cameras can acquire images with proper spatial resolution to allow the identification of plant species based on their location, shape, color and texture features. Using expensive hyperspectral images may result in substantial improvements in this process. The integration of these images with a machine-learning procedure can achieve high recognition levels for crop vs. weed discrimination (Zhang \& Slaughter, 2011; Zhang et al., 2012a).

In order to discriminate individual plant species it is possible to create image databases for all the species of interest, using their spectral signatures and/or their characteristic shape features (Gerhards \& Oebel, 2006; Weis \& Gerhards, 2007; López-Granados et al. 2008). Berge et al. (2008) used an object-oriented algorithm ("Weed Finder") for the automatic 
detection of broadleaved weeds in cereals. The results obtained in two experimental fields show that the estimates by the program and the corresponding true values of total broad-leaved weed density and weed cover were positively correlated, but there were serious dispersion and discrepancy from the 1:1 relationships (Fig. 3).
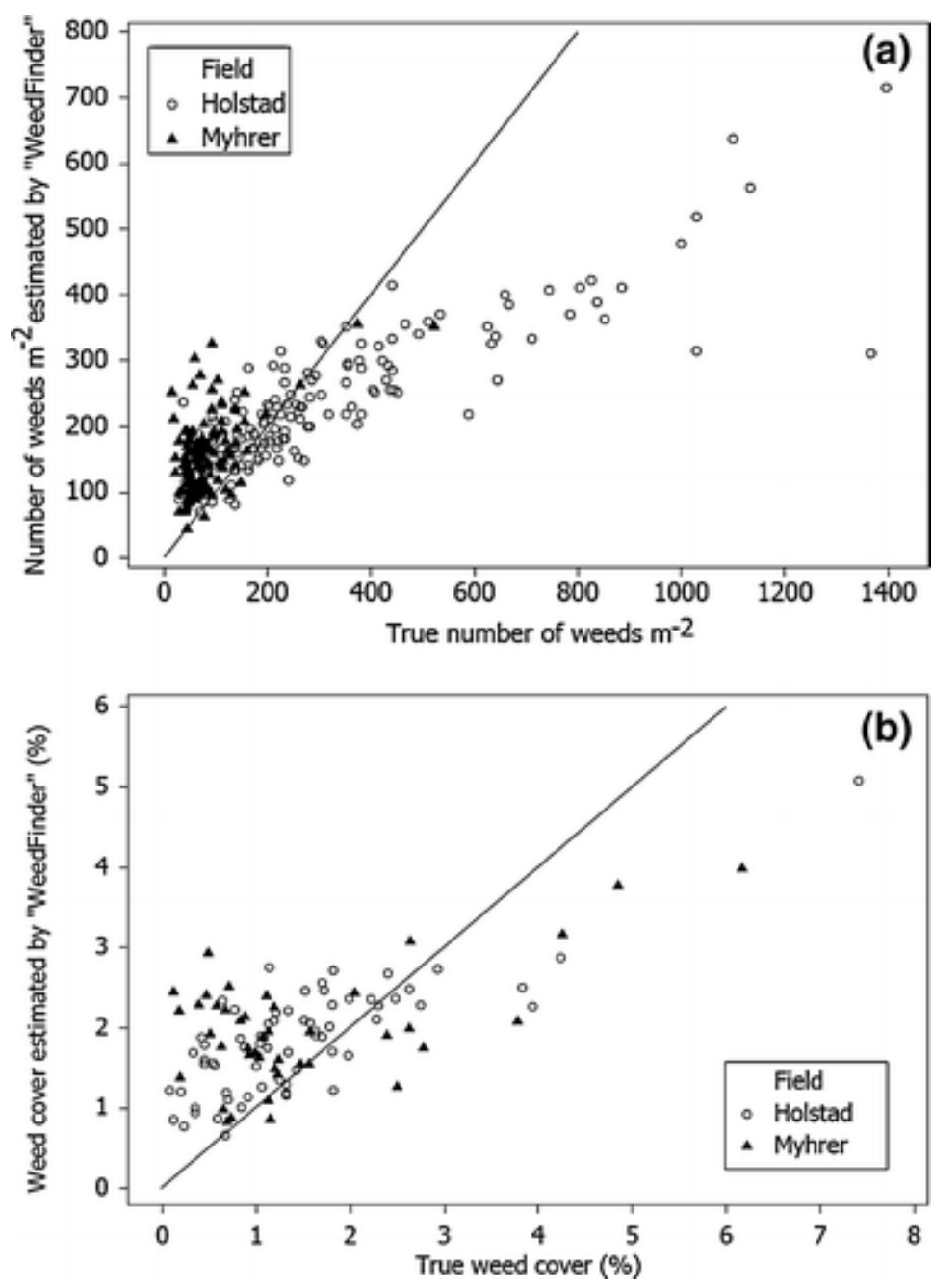

Fig. 4. True values versus "WeedFinder" estimated values of: (a) Total broad-leaved weed density and (b) Total broad-leaved weed cover in two wheat fields (Myhrer and Holstad) (Berge et al., 2008) 
3D modeling has been recently proposed for the morphological characterization of weed plants (Andujar et al 2018). These techniques can be based on visible images (Arvidsson et al., 2011), LiDAR (Guo et al., 2017), structured light (Nguyen et al., 2015), spectroscopy (Gutierrez et al., 2016), thermal images (Ludovisi et al., 2017), ultrasound (Andujar et al 2011), etc.

In order to practice SSWM, in addition to the weed sensing system, it is necessary to implement a weed management DSS and have a precision weed control device, such as a boom sprayer having independent boom sections or nozzles or a precise physical weed removal actuator (Christensen et al., 2009; Fennimore et al., 2016).

According with a relatively simple approach, weed control actuator, either chemical or physical, will be started automatically when estimated total weed cover in a given area is higher than experimentally determined thresholds. However, and due to the relatively long processing time of all these processes, this approach has some limitations to be used for online actuation. In addition, some aspects such as leaf overlapping or plant biomass quantification still need further research.

The most powerful method capable of robust, automated in-field discrimination of individual plant species is based upon hyperspectral imaging. This principle has been used in various horticultural crops for automated weed control (Zhang et al., 2012b; Fennimore et al., 2016). To translate weed maps into spray control maps, the predominant object classification (weed, crop, soil) in each region of the hyperspectral image determined the spray decision for that zone.

Currently, he use of Artificial Intelligence models is replacing some of the last decade developments. The concept is wide and many machinelearning processes can provide novel tools for online weed identification thought image processing (Liakos et al 2018; Yu et al., 2019). These fast analysis algorithms be used in conjunction with smart sprayers to accurately apply herbicides site-specifically. Various commercial initiatives using leading-edge hardware, software and artificial intelligence have already yielded equipment capable to detect weeds, decide the action to be taken and act immediately. Blue River Technology, a Silicon Valley startup, used computer vision and machine learning to identify plant species -both crops 
and weeds- with a high accuracy, and then artificial intelligence algorithms to make spraying decisions on the spot.

Custom nozzle designs enabled spraying individual plants. EcoRobotix, a small Swiss company, has designed, constructed and commercialized a small robotic unit equipped with a camera for weed recognition, a powerful computer with data processing using artificial intelligence algorithms and a set of movable nozzles that deposit herbicide microdoses in a targeted way. Deepfield Robotics, a Bosh startup, has developed an autonomous weeding machine equipped with a weed detection camera, a machine learning system and a mechanical weeding mechanism that destroy individual plants. Bosch has recently teamed up with Bayer, the giant German chemical firm, for a "smart spraying" research project using the detection and decision making technologies developed for BoniRob.

\section{References}

Andújar D, Escola A, Dorado J et al (2011) Weed discrimination using ultrasonic sensors. Weed Res 51:543-547

Andújar D, Calle M, Fernández-Quintanilla C et al (2018) Threedimensional modeling of weed plants using low-cost photogrammetry. Sensors 18: 1077; doi:10.3390/s18041077

Arvidsson S, Perez-Rodriguez P, Mueller-Roeber B (2011) A growth phenotyping pipeline for Arabidopsis thaliana integrating image analysis and rosette area modeling for robust quantification of genotype effects. New Phytol 191:895-907

Barroso J, Fernàndez-Quintanilla C, Ruiz D et al (2004) Spatial stability of Avena sterilis ssp. ludoviciana populations under annual applications of low rates of imazamethabenz. Weed Res. 44:178-186

Berge T, Aastveit A, Fykse H (2008) Evaluation of an algorithm for automatic detection of broad-leaved weeds in spring cereals. Precision Agric 9:391-405

Brown RB, Noble SD (2005) Site-specific weed management: sensing requirements - what do we need to see? Weed Sci 53: 252-258

Castaldi , Pelosi F, Pascucci S et al (2017) Assessing the potential of images from unmanned aerial vehicles (UAV) to support herbicide patch spraying in maize. Precision Agric 18:76-94 
Castillejo-González IL, de Castro AI, Jurado-Expósito M et al (2019) Assessment of the persistence of Avena sterilis 1. patches in wheat fields for site-specific sustainable management. Agronomy 9:30

Christensen S, Heisel T, Walter AM et al (2003) A decision algorithm for patch spraying. Weed Res 43:276-284

Christensen S, Sogaard HT, Kudsk P et al (2009) Site-specific weed control technologies. Weed Res 49:233-241

Dammer KH (2016) Real-time variable-rate herbicide application for weed control in carrots. Weed Res 56:237-246

Dammer KH, Wartenberg G (2007) Sensor-based weed detection and application of variable herbicide rates in real time. Crop Prot 26:270-277

de Castro AI, López Granados F, Gómez-Candón D et al (2013) In-season site-specific control of cruciferous weeds at broad-scale using quickbird imagery. 9th European Conference on Precision Agriculture (9th ECPA). Lleida, Spain, Universidad de Lleida.

de Castro AI, Jurado-Expósito M, Peña-Barragán JM et al (2012) Airborne multi-spectral imagery for mapping cruciferous weeds in cereal and legume crops. Precision Agric 13:302-321

de Castro AI, Torres-Sánchez J, Peña JM et al (2018) An automatic random forest-OBIA algorithm for early weed mapping between and within crop rows using UAV imagery. Remote Sensing 10:285

Felton WL, Mccloy KR (1992) Spot spraying. Agricultural Eng 73:9-12

Fennimore SA, Slaughter DC, Siemens MC et al (2016) Technology for automation of weed control in speciality crops. Weed Tech 30:823-837

Fernandez-Quintanilla C, Dorado J, San Martin C at al. (2011) A five-step approach for planning a robotic site-specific weed management program for winter wheat. In: Gonzalez-de-Santos P \& Rabatel G (eds) RHEA2011. Robotics and associated high-technologies and equipment for agriculture. Montpellier. pp 3-12

Fernandez-Quintanilla C, Dorado J, Andujar D et al (2018) Is the current state of the art of weed monitoring suitable for site-specific weed management in arable crops? Weed Res 58:259-272

Franco C, Pedersen SM, Papaharalampos H et al (2017) The value of precision for image-based decision support in weed management. Precision Agric 18:366-382

Gao J, Liao W, Nuyttens D et al (2018) Fusion of pixel and object-based features for weed mapping using unmanned aerial vehicle imagery. Int $\mathbf{J}$ of Appl Earth Obs and Geoinformation 67:43-53

Gerhards R and Oebel H (2006) Practical experiences with a system for sitespecific weed control in arable crops using real-time image analysis and GPS-controlled patch spraying. Weed Res 46:185-193 
Gómez-Candón D, López-Granados F, Caballero-Novella J et al (2012a) Sectioning remote imagery for characterization of Avena sterilis infestations. Part A: Weed abundance. Precision Agric 13:322-336

Gómez-Candón D, López-Granados F, Caballero-Novella J et al (2012a) Sectioning remote imagery for characterization of Avena sterilis infestations. Part B: Efficiency and economics of control. Precision Agric 13:337-350

Gonzalez-de-Santos P, Ribeiro A, Fernandez-Quintanilla C et al (2016) Fleets of robots for environmentally-safe pest control in agriculture. Precision Agric 1-41

Gray CJ, Shaw DR, Gerard D et al (2008) Utility of multispectral imagery for soybean and weed species differentiation. Weed Tech 22:713-718

Griffin TW (2016) Adoption of precision agricultural technology in Kansas. Kansas State University.Department of Agricultural Economics Extension. Publication. KFMA Research Article KSU-AgEcon-TG2016. https://www.agmanager.info/adoption-precision-agriculturaltechnology-kansas. Accessed 21 January 2017

Gutiérrez PA, López-Granados F, Peña-Barragán JM et al (2008) Mapping sunflower yield as affected by Ridolfia segetum patches and elevation by applying evolutionary product unit neural networks to remote sensed data. Comp and Elect in Agric 60:122-132

Gutjar C, Gerhards R (2010) Decision rules for Site-Specific Weed Management. In: Oerke EC et al (eds) Precision Crop Protection -the Challenge and Use of Heterogeneity. Springer Science+Business Media. pp 223-239

Hengl $\mathrm{T}$ (2006) Finding the right pixel size. Comp and Geosciences 32:1283-1298

Huang H, Deng J, Lan Y et al (2018) Accurate weed mapping and prescription map generation based on fully convolutional networks using UAV imagery. Sensors 18, 3299. https://doi.org/10.3390/s18103299

Jiménez-Brenes FM, López-Granados F, Torres-Sánchez J et al (2019) Automatic UAV-based detection of Cynodon dactylon for site-specific vineyard management. PLOS ONE 14, e0218132. https://doi.org/10.1371/journal.pone.0218132

Jurado-Expósito, M., de Castro, A.I., Torres-Sánchez, J., Jiménez-Brenes, F.M., López-Granados, F., 2019. Papaver rhoeas L. mapping with cokriging using UAV imagery. Precision Agric. https://doi.org/10.1007/s11119-019-09635-z

Lamastus-Stanford FE, Shaw D R (2004) Evaluation of site-specific weed management implementing the herbicide application decision support system (HADSS). Precision Ag 5:411-426 
Lambert JPT, Hicks HL, Childs DZ et al (2017) Evaluating the potential of Unmanned Aerial Systems for mapping weeds at field scales: a case study with Alopecurus myosuroides. https://doi.org/10.1111/wre.12275

Liakos K, Busato P, Moshou D et al (2018) Machine learning in agriculture: a review. Sensors 18: p. 2674

López-Granados F, Peña-Barragan JM, Jurado-Exposito M et al (2008) Multispectral classification of grass weeds and wheat (Triticum durum) using linear and nonparametric functional discriminant analysis and neural networks. Weed Res 48:28-37

López-Granados F, Torres-Sánchez J, Serrano-Pérez A et al (2016) Early season weed mapping in sunflower using UAV technology: variability of herbicide treatment maps against weed thresholds. Precision Agric 17:183-199

Louargant M, Jones G, Faroux R (2018) Unsupervised classification algorithm for early weed detection in row-crops by combining spatial and spectral information. Remote Sensing 10, 761. https://doi.org/10.3390/rs10050761

Ludovisi R, Tauro F, Salvati R et al (2017) UAV-based thermal imaging for high-throughput field phenotyping of black poplar response to drought. Front Plant Sci 8:1681. https://doi.org/10.3389/fpls.2017.01681

Lutman PJWand Miller PCH (2007) Spatially variable herbicide application technology; opportunities for herbicide minimisation and protection of beneficial weeds. Research Review No. 62, Home-Grown Cereals Authority (HGCA), UK

Montull JM, Rydahl P (2019) CPOweeds: DSS for multispecies weed control in cereals crops. In: Decision Support Systems for Weed Management

Neeser C, Dille JA, Krishnan G et al (2004) WeedSOFT®: a weed management decision support system. Weed Sci 52:115-122

Parsons DJ, Benjamin L, Clarke J et al (2009) Weed Manager-A modelbased decision support system for weed management in arable crops. Comput and Elect in Agr 65: 155-167

Peña JM, Torres-Sánchez J, de Castro AI et al (2013) Weed Mapping in early-season maize fields using object-based analysis of unmanned aerial vehicle (UAV) images. PLoS ONE 8, e77151. https://doi.org/10.1371/journal.pone.0077151

Peña-Barragán JM, López-Granados F, Jurado-Expósito M et al (2007) Mapping Ridolfia segetum patches in sunflower crop using remote sensing. Weed Res 47:164-172 
Peña-Barragán JM, López-Granados F, Jurado-Expósito M et al (2010) Sunflower yield related to multi-temporal aerial photography, land elevation and weed infestation. Precision Agric 11:568-585

Pérez-Ortiz M, Peña JM, Gutiérrez PA et al (2015) A semi-supervised system for weed mapping in sunflower crops using unmanned aerial vehicles and a crop row detection method. Applied Soft Computing 37:533-544

Pérez-Ortiz M, Peña JM, Gutiérrez PA et al (2016) Selecting patterns and features for between- and within- crop-row weed mapping using UAVimagery. Expert Systems with Applications 47:85-94

Peteinatos G, Weis M, Andujar D et al. 2014. Potential use of ground-based sensor technologies for weed detection. Pest Management Science 70, 190-199

Pflanz M, Nordmeyer H, Schirrmann M (2018) Weed mapping with UAS imagery and a bag of visual words based image classifier. Remote Sensing 10, 1530. https://doi.org/10.3390/rs10101530

Rasmussen J, Nielsen J, Garcia-Ruiz F (2013) Potential uses of small unmanned aircraft systems (UAS) in weed research. Weed Res 53:242248

Rydahl P, Berti A, Munier-Jolain N (2008) 24-Decision support systems (DSS) for weed control in Europe-state-of-the-art and identification of 'best parts' for unification on a European level. Available from: https://www.researchgate.net/publication/228431432_O_24- Accessed Feb 07201

Torres-Sánchez J, López-Granados F, de Castro AI et al (2013) Configuration and specifications of an unmanned aerial vehicle (UAV) for early site specific weed management. PLoS ONE 8, e58210. https://doi.org/10.1371/journal.pone.0058210

Sønderskov M, Rydahl P, Bojer AM et al (2016) Crop Protection OnlineWeeds: A case study for agricultural decision support systems. In: Papathanasiou J (ed), Real-World Decision Support Systems. Ploskas, I. Linden. pp 303-320

Weis M, Gerhards R (2007) Feature extraction for the identification of weed species in digital images for the purpose of site-specific weed control. In: Stafford JV (ed) Precision Agriculture. Wageningen Academic Publishers, Wageningen, The Netherlands pp 537-545

Yost MA, Sudduth KA, Walthall CL et al (2019) Public-private collaboration toward research, education and innovation opportunities in precision agriculture. Precision Ag. 20:4-18

Yu J, Sharpe SM, Schumann AW et al (2019) Deep learning for imagebased weed detection in turfgrass. Eur J of Agronomy 104:78-84 
Zhang Y and Slaughter DC (2011) Hyperspectral species mapping for automatic weed control in tomato under thermal environmental stress. Comput and Elect in Agr 77:95-104

Zhang Y, Slaughter DC, Staab ES (2012a) Robust hyperspectral visionbased classification for multi-season weed mapping. Journal of Photogrammetry and Remote Sensing 69:65-73

Zhang Y, Staab ES, Slaughter DC et al (2012b) Automated weed control in organic row crops using hyperspectral species identification and thermal micro-dosing. Crop Prot. 41:96-105 